\title{
MANAGEMENT SCHOLARSHIP'S CONTRIBUTION TO CLIMATE CHANGE RESEARCH: A BIBLIOMETRIC ANALYSIS
}

\author{
FRANZ WOHLGEZOGEN \\ Department of Management \& Marketing \\ University of Melbourne \\ Australia \\ ANGELA McCABE \\ La Trobe University \\ TOM OSEGOWITSCH \\ University of Melbourne \\ JOERI MOL \\ University of Melbourne
}

\begin{abstract}
As climate change pervades natural and social systems, the integration of social sciences in interdisciplinary climate change research is crucial but often lacking. In this study we use bibliometric analyses of management research on climate change to understand how management scholars have navigated interdisciplinarity, and what impact their efforts had on top-tier climate change research. We find that management scholarship (1) features substantial engagement with an interdisciplinary knowledge base through backward references, and (2) fails to attract the attention of climate change research in top-tier interdisciplinary journals, as evidenced in very low and stagnant forward citations.
\end{abstract}

\section{INTRODUCTION}

Climate change ${ }^{\mathrm{i}}$ represents a "wicked problem par excellence" (Termeer, Dewulf, \& Breeman, 2013, p. 28). The assessment of a changing climate's impact and the formulation of adaptation and mitigation strategies involve a high degree of complexity as well as uncertainty, and require joint efforts by diverse actors with diverging values and interests (Head, 2008). Prima facie, the social sciences offer a wealth of knowledge to facilitate and stimulate this multistakeholder process (Weaver, Mooney \& Allen, 2014). Research in management and business, in particular, has the capacity to support climate action by harnessing its considerable insights into, among other, the management of stakeholder relationships, corporate practices, organizational change, and consumer behaviour.

In this paper we examine the extent to which management research, broadly defined, has fulfilled its potential to contribute its unique perspective to climate change over the last four decades. To that end we curate two bibliometric datasets of research papers from management disciplines and from the journals Nature and Science published between 1980-2018, as well as all items cited by and citing these papers. Our study is guided by three research questions. First, we explore the question of management scholarship's engagement with the phenomenon of climate change per se. Second, we address the extent to which management scholarship has engaged with climate change research originating in other disciplines. Finally, we consider 
management scholarship's impact on climate change research appearing outside the discipline, notably in the top-tier interdisciplinary journals Science and Nature. Given that both journals exhibit greater interdisciplinarity in their knowledge base (i.e. backward references to other disciplines) than $99.7 \%$ of other journals (Gates et al., 2019, p.34), examining the degree to which management scholarship is noticed by these journals constitutes a conservative test of interdisciplinary impact.

We find that management research on climate change does substantively engage with interdisciplinary sources, but is trailing other social science disciplines in its interdisciplinary impact. We discuss the implications of these results for management scholarship's capacity to help address the global challenge of climate change.

\section{CONCEPTUAL FOUNDATION}

The concept of interdisciplinarity is central to our analyses of management research on climate change and such scholarship's impact. The concept permits us to systematically assess the depth and breadth of the intellectual inspiration scholars draw from prior research, and the reach their insights and findings have once published.

We adopt Strathern's (2004) and Bjurstrom and Polk's (2011) broad conceptualisation of interdisciplinarity as research activities transgressing disciplinary boundaries. We further distinguish narrow interdisciplinarity, connecting disciplines with similar epistemologies (e.g. physics and geology) from broad interdisciplinarity, connecting disciplines with dissimilar epistemologies (e.g. physics and sociology). Connecting the natural and social sciences is the most distinct example of broad interdisciplinarity (Bjurstrom \& Polk, 2011).

\section{METHODS AND DATA}

To address our research questions we compiled two bibliometric datasets using Clarivate's Web of Science (WoS) database. The first dataset, referred to as the Management Climate Change Research (MCCR) dataset, comprises climate change-related articles in management journals from 1980-2018. The second dataset, referred to as the Science/Nature Climate Change Research (SNCCR) dataset, comprises climate change-related articles published in the interdisciplinary journals Science and Nature from 1980-2018. Both datasets contained information about backward citations, i.e. references to prior research, and forward citations, i.e. references made to the items in our datasets.

Our search strategy employed inclusive search terms. The following string was used for the topic search (field "TS") for English-language items published between 1980-2018 listed in the Science Citation Index Expanded (SCIE), Social Sciences Citation Index (SSCI), and Arts and Humanities Citation Index (AHCI):

$$
\begin{aligned}
& T S=\left(\left("{ }^{*} \text { climat }^{*} \text { chang*") or ("*climat* warming } * "\right) \text { or }\left(" * \text { global temperature }{ }^{* \prime \prime}\right)\right. \text { or } \\
& \text { ("*global warming*") or ("*greenhouse gas *") or ("*greenhouse effect*") or } \\
& \text { ("greenhouse warm*") or ("anthropogenic warming*") or ("anthropogenic emission*") } \\
& \text { or ("climat* model*")) }
\end{aligned}
$$

For the MCCR dataset, we restricted results to the four WoS subject categories (field "WC") related to management: "business", "management", "business, finance", and "operations 
\& management science" (referred to as the "BMFO disciplines" herein). The final MCCR dataset included 1724 unique articles, with a total of 94,692 backward references, and 42,012 forward citations.

For the SNCCR dataset we used the same topic search string (and identical parameters concerning language, time frame, document type) as for the management dataset, but restricted results to the journals Science and Nature. The final SNCCR dataset included 2,981 unique articles, with a total of 59,295 backward references, and 600,710 forward citations.

For our analyses of interdisciplinarity, the disciplinary classification of articles is of central importance. We follow prior bibliometric studies of interdisciplinarity (Leydesdorff, Rafols, \& Chen, 2013, Solomon, Carley, \& Porter, 2013) in utilizing WoS's subject categories (field "WC") to delineate disciplinary boundaries and interdisciplinary connections. For our analyses, we rely on journals' subject categories to quantify papers' degree of narrow or broad interdisciplinarity of backward references. Specifically, we created three groups to aid in delineating degrees of narrow and broad interdisciplinary engagement. The social science ('SOCS') disciplines group comprises all 3,274 journals that are listed in the Social Science Citation Index. The Climate Change Core (' $\mathrm{CCC}$ ') disciplines group comprises all 1,061 journals that are associated with the ten most common WoS subject categories in climate change research, specifically "environmental sciences", "meteorology and atmospheric sciences", "multidisciplinary geosciences", "ecology", "environmental studies", "energy and fuels", "water resources", "physical geography", "multidisciplinary sciences" and "environmental engineering". Of these ten, only environmental studies is associated with the SOCS. Collectively, the 10 categories account for two thirds of all climate change research (using the search string above) across the WoS SCIE, SSCI and AHCE databases. The third group, the 'BMFO' disciplines group, comprises all 494 English-language journals from the business, management, finance and operations disciplines. Lastly, in our analyses of narrow and broad interdisciplinarity we distinguish, for more gradation, between references to the native discipline, and non-native disciplines. ${ }^{\text {ii }}$

\section{RESULTS}

\section{Engagement with the phenomenon of climate change}

Management scholars are not oblivious to the problems facing the planet and humankind. Over the period 1980-2018, 1,725 items were published across 257 different journals. More specifically, 0.35\% of all items published in BMFO journals between 1980 and 2018 were related to climate change, about half the scholarly attention the topic received across all the social science disciplines (0.7\%). However, management scholarship on climate change grew significantly after the mid-2000s, at a rate comparable to that of social science scholarship on climate change overall. It is particularly encouraging that a remarkable $64 \%$ of the management research on the topic appeared in journals that ranked in their discipline's top quartile as measured by Journal Impact Factor.

\section{Interdisciplinary research engagement}

Management scholars' referencing of climate change research from other disciplines constitutes interdisciplinary engagement. The quantitative assessment of the MCCR items' 
backward references reveals both a substantial narrow interdisciplinarity and broad interdisciplinarity. References to journals outside the native discipline was evident in $92 \%$ of all items in the dataset. Of the 94,692 backward references, $7.3 \%$ were made to non-native disciplines within the BMFO journal group (e.g. an item from a finance journal referencing research from management journals), $10.3 \%$ to environmental studies (the single social science discipline in the CCC group) and 10.1\% to other social sciences (principally economics). This represents the degree of narrow interdisciplinarity, i.e. engagement with epistemologically similar disciplines. MCCR items also include a notable amount of references to journals outside the social sciences, constituting evidence of broad interdisciplinary engagement: $7.4 \%$ of references go to SCIE-indexed journals from the CCC journal group, and $13.2 \%$ to other disciplines. The journals Science and Nature are well-represented in the broad interdisciplinary engagement efforts: they are among the top 5 most frequently cited journals outside the BMFO group. We also note a substantial share $(34 \%)$ of non-journal references. These prominently include books on climate-related research, governmental and other reports (such as the IPCC reports).

Figure 1 visualises how these patterns of backward referencing have evolved over time. After 2010, the share of references to SCIE and to SSCI disciplines in the CCC journal group has stabilized at around $7 \%$ and $10 \%$ respectively. The percentage of native disciplinary references has increased from $15 \%$ in 2010 to $22 \%$ in 2018 , replacing primarily non-journal references. The general trend of substantial and sustained broad interdisciplinary engagement holds true across all four BMFO group disciplines, with the management discipline showing the strongest engagement with the CCC group disciplines.

Figure 1 about here

\section{Interdisciplinary research impact}

Crucial for the management disciplines' contribution to addressing climate change is that the research is noticed and cited outside of its disciplinary boundaries. Of the 2,981 items in the SNCCR dataset, only 26 items reference research from BMFO disciplines. Of the 1,745 items in the MCCR dataset, only 19 feature among the 48 unique BMFO items referenced by the SNCCR items. The low engagement of SNCCR items with research from management-related disciplines should be considered in a context of (1) increasing interdisciplinarity of research published in Science and Nature, and (2) persistent low overall engagement with and integration of social science research. From 1980 to 2018, the number of unique disciplines cited by the 2,935 SNCCR items grew, from only eight different disciplines (all from the natural sciences) in 1980 to a total of 124 different disciplines (38 of them from the social sciences) in 2018. Despite this broadening of the knowledge base, however, the share of references to articles from social science disciplines remained low, reaching their highest level at just under $6 \%$ of total references in the year 2016 (see Figure 2). Environmental studies, economics, and anthropology were the most frequently referenced social science disciplines. 
Figure 2 about here

\section{DISCUSSION}

Climate change is a series of bio-physical processes, but it is also part of a complex social process: our understanding of, and our responses to, climate change are deeply rooted in human behaviour. As such, interdisciplinary work is imperative. Yet bringing together the natural and social science communities through coequal research partnerships remains a formidable challenge in the face of ingrained epistemic and methodological boundaries that tend to divide disciplines (Mooney, Duraiappah, \& Larigauderie, 2014; Victor, 2015). Some authors suggest that 'the social' of climate change has been downplayed and mostly treated in a reductionist fashion (Victor, 2015; Billi, Blanco, \& Urquiza, 2019).

In this paper we attempted to establish the stylised facts (Helfat, 2015) regarding management scholarship on climate change - its concern with the phenomenon in general, as well as with climate change research appearing in other disciplines. We find that significant and growing attention is accorded to the topic of climate change across management-related disciplines. We also find that a substantial proportion of the management items in the MCCR dataset draw their knowledge base from a broad variety of sources, including sources from outside the social sciences. Hence, we confirm substantial narrow as well as broad interdisciplinary engagement in management scholarship on climate change.

However, our bibliometric analysis also reveals that management scholarship is struggling to achieve impact on top-tier climate change research outside the discipline. This finding is cause for concern considering the impact achieved by some other social sciences, and the growing volume of management research on climate change. The disparity between interdisciplinary engagement and interdisciplinary impact suggests that much more effort is needed to connect insights from management scholarship with the broader, interdisciplinary discourse on climate change.

\section{ENDNOTES}

' The Intergovernmental Panel on Climate Change's (IPCC) 2014 Assessment Report provides a useful definition of climate change: "Climate change refers to a change in the state of the climate that can be identified ... by changes in the mean and/or the variability of its properties and that persists for an extended period, typically decades or longer. Climate change may be due to natural internal processes or external forcings such as modulations of the solar cycles, volcanic eruptions and persistent anthropogenic changes in the composition of the atmosphere or in land use" (IPCC, 2014, p. 120).

ii For example, an MCCR item published in Organization \& Environment, a journal whose primary discipline is management, may contain references to items published in finance journals. We designate these nonnative references within the BMFO disciplines group as an indicator for narrow interdisciplinarity. For items from the SNCCR dataset we base the native/non-native designation on the item-level (not journal-level) disciplinary affiliation, since both Science and Nature are in the multidisciplinary sciences journal category. Using the item-level disciplinary designation allows for a more precise assessment of interdisciplinary referencing in these articles.

\section{REFERENCES AVAILABLE FROM THE AUTHORS}


Figure 1: Interdisciplinary engagement in climate change-related management research (MCCR dataset)
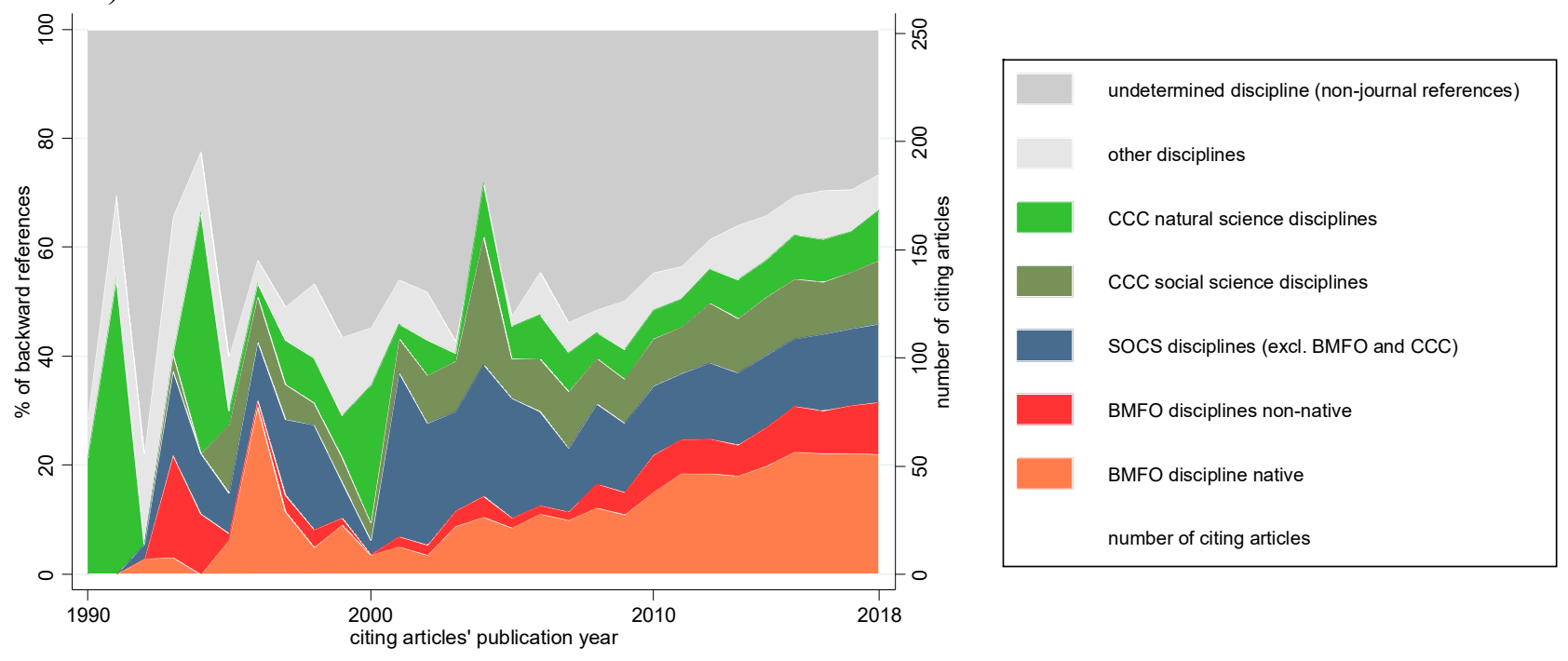

Figure 2: Interdisciplinary impact on climate change research in Science and Nature (SNCCR dataset)

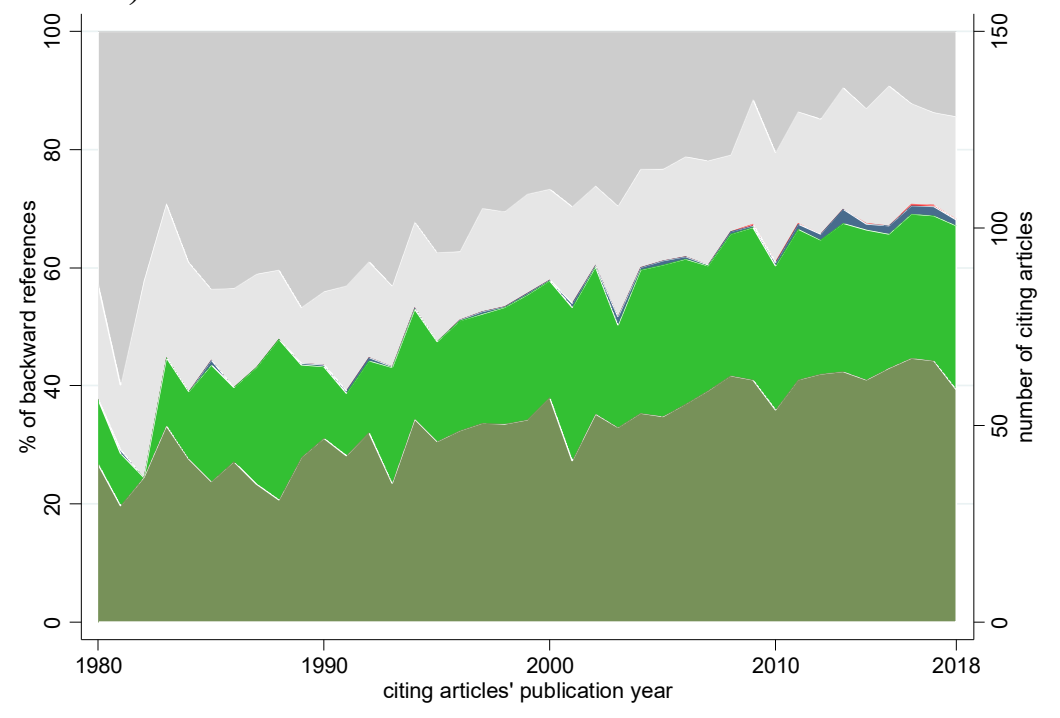

\begin{tabular}{|l|}
\hline undetermined discipline (non-journal references) \\
other disciplines \\
BMFO disciplines \\
SOCS disciplines (excl. BMFO and CCC) \\
CCC disciplines non-native \\
CCC discipline native \\
number of citing articles
\end{tabular}




\section{University Library}

\section{- M M N E R VA A gateway to Melbourne's research publications}

Minerva Access is the Institutional Repository of The University of Melbourne

Author/s:

Wohlgezogen, F;MCCABE, A;Osegowitsch, T;Mol, J

Title:

Management Scholarships Contribution to Climate Change Research: A Bibliometric Analysis

Date:

2020

Citation:

Wohlgezogen, F., MCCABE, A., Osegowitsch, T. \& Mol, J. (2020). Management Scholarships Contribution to Climate Change Research: A Bibliometric Analysis. [Abstract]. Proceedings of 80th Annual Meeting of the Academy of Management, 2020 (1), pp.18380-18380. https:// doi.org/10.5465/AMBPP.2020.193.

Persistent Link:

http://hdl.handle.net/11343/247851 